GU J Sci, Part C, 8(1): 182-191 (2020)

Gazi Üniversitesi
Fen Bilimleri Dergisi
PART C: TASARIM VE TEKNOLOJI
http://dergipark.gov.tr/gujsc

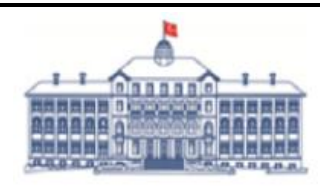

Use of K-Means Clustering Algorithm for Lesion Segmentation in Dermoscopic Images

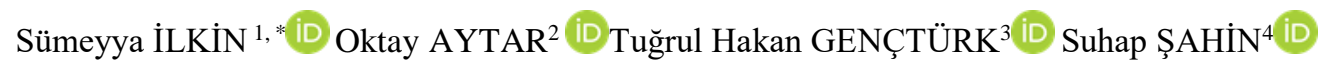 \\ ${ }^{1,3,4}$ Kocaeli University Faculty of Engineering, Department of Computer Engineering, 41001, İzmit/KOCAELI \\ ${ }^{2}$ Bolu Abant İzzet Baysal University Faculty of Eng., Dept. of Electrical Electronics Eng., 14030, Gölköy/BOLU
}

\section{Article Info:}

Research article Received: 26/09/2019 Revision: 08/02/2020 Accepted: 08/02/2020

\section{Highlights \\ - Lesion Segmentation. \\ - Melanoma. \\ - K-means Clustering for \\ melanoma segmentation.}

\section{Keywords}

Medical Image Processing Melanoma Skin Cancer Lesion Segmentation K-Means Clustering Algorithm

Mean Shift Algorithm Canny Edge Detection Algorithm

\section{Graphical/Tabular Abstract}

In this study, the segmentation of lesion regions in skin images is performed with K-mean clustering algorithm in order to increase the accuracy of diagnosis made by doctors. The system is tested by selecting $\mathrm{K}$ center number 2 and 4 values. A melanoma data set has been used for testing. Peak Signal Noise Ratio (PSNR) and Correlation Coefficient (CC) metrics values has been obtained for analyzing of the study. The performance evaluation of the study has been done by using enhanced Canny edge detection and Mean shift algorithms.

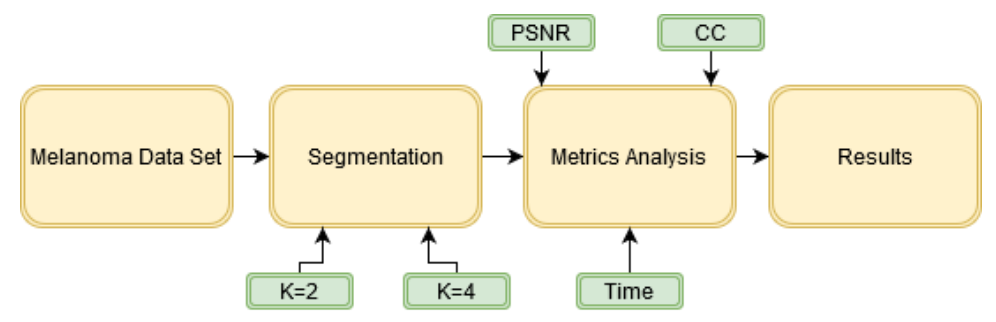

Figure A. Block diagram of the proposed study

Purpose: Melanoma diagnoses are mostly made by pathological visual evaluation of the skin. This evaluation is mostly subjective since it is based on the observations of the doctors. Therefore, computer-assisted systems are been using to increase the correct diagnosis rates in cases. In this study, lesion regions segmentation is performed. K-mean clustering algorithm is used for the segmentation process.

Theory and Methods: Lesion segmentation is performed by using K-mean clustering algorithm on images with melanoma type skin cancer lesions taken from a dataset. The system has been tested by selecting $\mathrm{K}$ center values 2 and 4 respectively and using all images separately.

Results: A data set consisting of 70 macroscopic melanoma skin cancer images is used for the test procedure. To measure the effectiveness of the system, it is analyzed using PSNR and CC metrics. The efficiency of this study is obtained by comparing it with the enhanced Canny edge detection algorithm and the mean shift algorithm. The proposed study gives the highest PSNR and correlation coefficient metric values when the $\mathrm{K}$ center value is selected 4 . The experimental results are presented and compared in Section 3.

Conclusion: Melanoma skin cancer lesion segmentation is presented in this study. The aim of this study is to obtain lesion areas in order to increase the correct diagnosis rates. The lesion regions and non-lesion regions obtained in the study are clustered according to their color values. In the lesion segmentation process, the K-means clustering algorithm is used and the system is tested by selecting the $\mathrm{K}$ center numbers 2 and 4 . The analysis of the obtained values is carried out using PSNR and CC metrics. At the same time, the operating times of the study are calculated. The performance of this study is evaluated by comparing Canny edge detection and Mean shift algorithm previously implemented by us. According to the metric results, it is observed that the segmentation performed by using the K-mean clustering algorithm which has selected center number equals to the 4 yielded more successful results. 
GU J Sci, Part C, 8(1): 182-191 (2020)

Gazi Üniversitesi
Fen Bilimleri Dergisi
PART C: TASARIM VE TEKNOLOJI
http://dergipark.gov.tr/gujsc

\title{
Dermoskopik Görüntülerde Lezyon Bölütleme İşlemlerinde K-ortalama Kümeleme Algoritmasının Kullanımı
}

\author{
Sümeyya İLKİN ${ }^{1, *(D)}$ Oktay AYTAR ${ }^{2}$ (D) Tuğrul Hakan GENÇTÜRK ${ }^{3}$ (D) Suhap ŞAHIN ${ }^{4}$ (D) \\ 1,3,4 Kocaeli University Faculty of Engineering, Department of Computer Engineering, 41001, İmit/KOCAELI \\ ${ }^{2}$ Bolu Abant İzet Baysal University Faculty of Engineering, Department of Electrical Electronics Engineering, 14030, Gölköy/BOLU
}

\begin{tabular}{l} 
Makale Bilgisi \\
\hline Araştırma makalesi \\
Başvuru: $26 / 09 / 2019$ \\
Düzeltme: $08 / 02 / 2020$ \\
Kabul: 08/02/2020 \\
Anahtar Kelimeler \\
\hline Medikal Görüntü İsleme \\
Melanom Cilt Kanseri \\
Lezyon Bölütleme \\
K-Ortalama Kümeleme \\
Algoritmast \\
Ortalama Kayma \\
Algoritmast \\
Canny Kenar Belirleme \\
Algoritmast
\end{tabular}

Keywords

Medical Image Processing Melanoma Skin Cancer Lesion Segmentation K-Means Clustering Algorithm

Mean Shift Algorithm Canny Edge Detection Algorithm

\begin{abstract}
$\ddot{O} z$
Melanom cilt kanserinin erken evrelerinde yapılan teşhisler, iyileşme prognozuna olan etkilerinden dolayı hayati önem taşımaktadır. Yapılan bu teşhisler büyük oranda cildin görsel değerlendirmesiyle yapılmaktadır. Dolayısıyla, yapılan bu görsel değerlendirme sonucu konulan teşhis çoğunlukla doktorların uzmanlığına bağlı olduğu için, sübjektif bir değerlendirme olmaktadır. Yapılan bu çalışmada, doktorlar tarafindan konulan teşhislerdeki doğruluk oranlarını artırmak için cilt görüntülerindeki lezyon bölgelerinin bölütleme işlemi K-ortalama kümeleme algoritması ile yapılmaktadır. Algoritmada, K merkezi sayısı 2 ve 4 değerleri seçilerek sistem test edilmektedir. Test aşamasında özel bir melanom veri seti kullanılmıştır. Elde edilen değerlerin analiz işlemleri, Tepe Sinyali Gürültü Oranı (PSNR) ve Korelasyon Katsayısı (CC) metrikleri kullanılarak gerçekleştirilmiştir. Yapılan bu çalışmanın performansı, daha önce tarafımızca gerçeklenen Canny kenar belirleme ve ortalama kayma algoritmaları ile karşılaştırılarak değerlendirilmiştir. Yapılan bölütleme işleminde, merkez sayısı 4 seçilen K-ortalama kümeleme algoritmasında en yüksek PSNR değeri 17,1591dB olarak tespit edilmiştir. Metrik sonuçlar incelendiğinde, K-ortalama kümeleme algoritmasında merkez sayısı 4 olarak seçildiğinde elde edilen sonuçların daha iyi olduğu gözlemlenmiştir.
\end{abstract}

\section{Use of K-Means Clustering Algorithm for Lesion Segmentation in Dermoscopic Images}

\begin{abstract}
The diagnosis of melanoma skin cancer in the early stages is of vital importance owing to the fact that their effects on the prognosis of recovery. The made of these diagnoses are mostly done with visual evaluation of the skin. Therefore, the stated diagnosis of as a result of visual evaluation of the skin is a subjective assessment that because it depends on the doctor's expertise. In this study, the segmentation of lesion regions in skin images is performed with K-mean clustering algorithm in order to increase the accuracy of diagnosis made by doctors. In the algorithm, the system is tested by selecting $\mathrm{K}$ center number 2 and 4 values. A special melanoma data set has been used during the testing. The analysis of the obtained values have been realized using Peak Signal Noise Ratio (PSNR) and Correlation Coefficient (CC) metrics. The performance of this study was evaluated by comparing Canny edge detection and Mean shift algorithm previously implemented by us. In this segmentation process, the selected center number is 4 in the $\mathrm{K}$-average clustering algorithm and in this situation the highest PSNR value is $17,1591 \mathrm{~dB}$. According to the metric results, it was observed that the segmentation performed by using the K-mean clustering algorithm which has selected center number equals to the 4 yielded more successful results.
\end{abstract}

\section{GİRIŞ (INTRODUCTION)}

Melanom, deriye rengini veren melanosit hücrelerde başlayan ve erken evrelerde teşhiş edildiğinde tedavi şans1 \%70'lere ulaşan bir cilt kanseri türüdür. Son 30 y1lda ülkemizde görülen melanom vakaları \%237 oranında artmıştır [1,2]. Melanom teşhisleri büyük oranda cildin patolojik görsel değerlendirilmesi ile yapılmaktadır. Fakat bu değerlendirme çoğunlukla doktorların gözlemlerine dayandığı için sübjektif 
olmaktadır. Günümüzde doktorlar cildin görsel değerlendirmesini dermatoskop adı verilen cihazları kullanarak yapmaktadırlar [3]. Çıplak gözle yapılan muayenelerde melanom vakalarında erken evre tanı şans1 \%60 iken, sayısal dermatoskop kullanılarak yapılan incelemelerde bu oran \%90'lara çıkmaktadır [2]. Dolayısıyla vakalardaki doğru teşhis oranlarını artırmak için bilgisayar destekli sistemler kullanılmaya başlanmıştır ve cilt görüntülerindeki lezyon bölgelerinin bölütlemesinde de sıklıkla kullanılmaktadır.

Yapılan çalışmalar incelendiğinde, kanser bölgelerinin bölütlenmesi alanında pek çok metot ve yöntem ile çalışıldığı gözlemlenmektedir. Alsmadi [4] bu çalışmasında, çene tümörünü erken evrelerinde teşhis etmek için panoramik röntgen görüntülerindeki çene lezyonlarının bölütlemesini gerçekleştirmiş olup, çene görüntüsünü bölütlere ayırmak ve çene lezyonlarının teşhisinde yardımcı olabilecek panoramik X-1şını görüntülerinde çene lezyon bölgesini tespit etmek için Melez Bulanık C-Ortalama ve Nötrosofik yaklaşımları kullanmıştır. Yapılan bu çalışmada, önerilen yaklaşımın performansını ve verimliliğini farklı açılardan değerlendirmek için alan hata metrikleri kullanılmış olup, doğruluk ve verimliliğini değerlendirmek için de özgüllük, duyarlılık ve benzerlik analizleri yapılmıştır. Önerilen yaklaşım, Hibrit Ateşböceği Algoritması ve Yapay Arı Kolonisi ile Bulanık C-Ortalama algoritması birlikte kullanılarak yapılan çalışmaların karşılaştırılması yapılmış ve FP (Yanlış Pozitif) oranı \% 6.1, TP (Doğru Pozitif) oranı $\%$ 90, özgüllük oranı 0.9412 , duyarlılık oranı 0.9592 ve benzerlik oranı 0.9471 olarak verilmiştir.

Li ve arkadaşları [5] bu çalışmasında, BT görüntülerindeki karaciğer alanlarını otomatik bölütlemek için bir yöntem önermişlerdir. Önerilen yöntem üç adımdan oluşmaktadır. İlk adımında, temel bileşen analizine dayanarak istatistiksel bir şekil modeli oluşturulmuş ve giriş görüntüsü eğrilik anizotropik difüzyon filtrelemesi kullanılarak yumuşatılmıştır. İkinci aşamasında, ortalama şekil modeli, bir test görüntüsünde kaba bir pozisyon elde etmek için eşikleme ve öklid mesafesi dönüşümü kullanılarak hareket ettirilmiştir. Son olarak, karaciğer yüzeyini doğru bir şekilde tespit etmek için, giriş görüntülerinin ve başlangiç yüzeyinin özelliklerini ve karş1lıklı ilişkilerini etkili bir şekilde bütünleştiren deforme olabilen bir grafik kesimi elde edilmiştir. Önerilen yöntemin, deney sonuçları ile karaciğer yüzeyinin tespiti için etkili ve başarılı bir yöntem olduğu gösterilmiştir.

Ahn ve arkadaşları [6], bu çalışmasında dermoskopik görüntülerin doğal özelliklerinden yararlanmak için yeni bir otomatik saliency tabanlı cilt lezyonu bölütleme yöntemi önermişlerdir. Önerilen çalışmada, çevre bölgelerden gelen ince kontrast ayrımcılı̆̆ının, görüntü arka planlarına karşı seyrek yapılanma hatalarının ölçülmesinin göze çarpma tespiti yoluyla aşılabileceği gösterilmiştir. Adaptif eşikleme, Chan bazlı seviye seti ve ekilen bölge yetiştiriciliği içeren lezyon bölütleme için belirlenmiş yöntemlerle karşılaştırılmıştır. Önerilen yöntem, diğer yöntemlerle karşılaştırıldığında daha yüksek sonuçlar verdiği ve en iyi genel ortalamaya $(\% 91,66)$ ve en iyi maksimum $(\% 97,52) /$ minimum $(\% 39,18)$ hassasiyete sahip olduğu görülmüştür.

Abbas ve arkadaşları [7] tarafından yapılan bu çalışmada, dermoskopik görüntü kalitesinin artırılması için, bölütlemeden önce Spline ve BSpline metotları birleşiminin kullanılmasını önermişlerdir. Uygulanan bu metodun başarı oranını artırdı ğı ve 70 tane dermoskopik görüntü üzerinde yapılan çalışmada başarım oranın $\% 97,21$ olarak hesaplandığı belirtilmiştir.

Huang ve arkadaşları [8] tarafından yapılan bu çalışmada, meme ultrason görüntüleri için yeni bir otomatik bölütleme şeması önerilmiştir. İlk olarak, meme ultrason görüntüsündeki lekeleri azaltmak için toplam varyasyon modeli kullanılmış, ardından filtrelenmiş görüntüyü çok sayıda alt bölgeye ayırmak için bölgesel istatistiklerden yararlanan grafik tabanlı bir yöntem uygulanmıştır. Özellik çıkarımı, özellik seçimi ve sınıflandırma içeren tümör bölgelerini tanımak için bir nesne tanıma yöntemi kullanılmıştır. Son olarak, tümörler olarak bilinen bölgelerin konturlarını daraltmak için aktif bir kontur modeli kullanılmıştır. Ultrason görüntüleri için geliştirilmiş olan hibrit bir otomatik bölütleme yöntemiyle karşılaştırıldığında, önerilen yöntem daha iyi performans sağladığı görülmüştür.

Wantanajittikul ve ark. [9] tarafından yapılan çalışmada; yanma yaralanmalarında meydan gelen yanıkların görüntülerinden yararlanılarak, ilk değerlendirmeyi yapma yeteneğine sahip otomatik bir sistem önerilmiştir. Önerilen sistemin yanık görüntü bölütleme kısmında, yanık yara alanını sağlıklı deriden ayırmak için Cr-transformasyonu, Luv transformasyon ve bulanık c-ortalama kümeleme tekniği kullanılmış olup bölütleme hatalarını azaltmak için de matematiksel morfoloji uygulanmıştır. Yanık derecesinin tanımlanması ve özellik vektörlerini çıkarmak için h-dönüşümü ve doku analizi kullanılmış olup, yanık derecesini belirlemek için de destek vektör makinesi (SVM) uygulanmıştır. Elde edilen sınıflandırma 
sonuçları, Bayes ve K'nin en yakın komşu sınıflandırıcıları ile karşılaştırılmıştır. Önerilen bölütleme algoritmasının, renkli yanık görüntüleri için iyi sonuçlar verdiği deneysel sonuçlarda görülmüştür.

Haider ve arkadaşları [10] tarafından yapılan bu çalışmada; HSI renk uzayı, bölütleme, ölçütleme ve ANN$\mathrm{K}$ ortalama kümeleme yöntemleri kullanılarak, cilt yaralarının iyileşip iyileşmediğini belirleyen bir algoritma gerçekleştirmişlerdir. Önerilen çalışmanın başarım oranı da \%89'dur.

$\mathrm{Bu}$ çalışmada, cilt görüntüleri üzerinde melanom lezyonlarının bölütleme işlemi K-ortalama kümeleme algoritması kullanılarak gerçekleştirilmektedir. Kullanılan kümeleme algoritması için 2 farklı merkez değeri seçilerek elde edilen sonuçlar PSNR ve CC metrikleri kullanılarak analiz edilmektedir. Yapılan bu çalışma, ön çalışma niteliğinde olduğu için, analiz işlemlerinde kullanılan doğruluk ve verimlilik gibi değerler elde edilememiş olup, çalışmanın verimliliğini ölçmek için PSNR ve CC metrik değerleri kullanılmıştır. Aynı zamanda, algoritma çalışma süreleri de hesaplanmaktadır. Elde edilen değerler kullanılarak en efektif sonuçları veren merkez sayısı tespit edilmektedir.

Çalışmanın organizasyonu şu şekildedir; 2 . bölümde, önerilen sistem ve bu çalışmada kullanılan yöntem anlatılmaktadır. 3.bölüm, elde edilen deneysel sonuçları ve analiz işlemlerini içermektedir. Son olarak 4.bölüm de ise sonuçlar ve öneriler yer almaktadır.

\section{2. ÖNERILLEN SISSTEM (PROPOSED SYSTEM)}

Bu çalışmada bir veri kümesinden alınan melanom tipte cilt kanserli lezyonların bulunduğu görüntüler üzerinde, lezyon bölütleme işlemi K-ortalama kümeleme algoritması kullanılarak gerçekleştirilmektedir. Sistemin sözde kodu Şekil 1 'de verilmektedir.

\begin{tabular}{|ll}
\hline Başlat: & Görüntü aç \\
& Görüntü boyutunu değiştir \\
& Görüntü tipini np.float32 tipine dönüştür \\
& K-ortalama için merkez sayısı (küme \\
& sayısı) ata \\
& Ortalama değerleri kullanarak merkezleri \\
& oluştur \\
& Her bir merkez için yeni ortalama değeri \\
& ata \\
& Elde edilen merkezleri uint8 tipine \\
& dönüştür \\
& Görüntüyü merkezlerin renk değerlerini \\
& kullanarak düzleştir \\
& Bölütlenen görüntünün boyutunu değiştir \\
& Yeni görüntüyü kaydet
\end{tabular}

Şekil 1. Sistem sözde kodu

Sözde kod incelendiğinde görüntü üzerinde bölütleme işlemine geçilmeden önce sistem çalışma süresinin azaltılması için yüksek çözünürlüklere sahip olan görüntülerde boyut küçültme işlemi yapılmaktadır.

\subsection{K-ortalama Kümeleme Algoritması (K-Means Clustering Algorithm)}

En çok tercih edilen kümeleme algoritmalarından biri olan K-ortalama kümeleme algoritması 1967 yılında J.B. MacQueen tarafindan geliştirilmiş̧ir [11]. Algoritmada kümeleme işlemi, girişte verilen merkez sayısına, $\mathrm{n}$ adet veri nesnesinden oluşan bir veri kümesini bölerek yapılmaktadır. Veri nesnesinde yer alan veriler sadece bir kümeye ait olmaktadır, küme kesişimine izin verilmemektedir [12]. 
Algoritmanın çalışma mantığı aşağıdaki gibidir [13];

- K merkez sayısını giriş parametresi olarak al

- Rastgele K adet merkez noktası seç

- Her veri ile rastgele belirlenen merkez noktaları arasındaki uzaklığı hesaplayarak veriyi merkez noktasına olan uzaklığı en az olacak şekilde bir kümeye ata

- Her küme için yeniden bir merkez noktası seç

- Yeni merkez noktalarına göre kümeleme işlemi yap

- $\mathrm{Bu}$ işleme kriter fonksiyonuna ulaşılana kadar devam et.

K-ortalama kümeleme algoritmasında kriter fonksiyonu olarak, karesel hata kriteri (the error sum of squares SSE) kullanılmaktadır. Algoritma sonucu oluşan kümelerden en düşük SSE değerine sahip kümeleme sonucunu veren kümeler, en iyi sonuç olarak kabul edilmektedir. SSE değeri Denklem 1 ile hesaplanmaktadır $[14,15]$.

$$
S S E=\sum_{i=1}^{k} \sum_{x=C_{i}} \operatorname{dist}^{2}\left(m_{i}, x\right)
$$

Denklem 1'de $m_{i}$ merkezleri, $C_{i}$ ise i. merkezde bulunan nesnelerin kümesini göstermektedir. Nesnelerin bulundukları kümenin merkez noktalarına olan uzaklıklarının karelerinin toplamı bu eşitlik kullanılarak hesaplanmaktadir.

\section{DENEYSEL SONUÇLAR (EXPERIMENTAL RESULTS)}

Çalışma kapsamında geliştirilen sistemin test işlemi için MED-NODE sisteminden alınmış 70 adet makroskopik melanom cilt kanseri görüntüsünden oluşan MED-NODE sisteminde kullanılmak üzere oluşturulan özel bir veri kümesi kullanılmıştır [16]. Kullanılan veri kümesi melanom alanları tespit edilmiş teşhisi konmuş görüntülerden oluşmaktadır. Dolayısıyla geliştirilen sistemle sadece lezyon alanlarının sayısal olarak elde edilmesi işlemi gerçekleştirilmektedir.

Yapılan çalışmalar incelendiğinde K-ortalama kümeleme algoritmasında kullanılan K merkez değeri seçiminin neye dayandırılarak yapıldığına dair açıklama veya gerekçelere çok rastlanmamaktadır [17]. Yapılan seçimler genellikle sübjektif olmakla birlikte, eğer küme sayısı belirli değil ise deneme yanılma metoduna sıklıkla dayandırılmaktadır [18]. Bu yüzden, kullanıcıların k merkez değerini çoğunlukla alandaki ve kullandıkları veri kümeleri üzerindeki deneyimlerine göre seçtiği gözlemlenmektedir [19]. Melanom alanlarının tespiti çalışmalarında kullanılan görüntülerde ağırlıklı olarak iki küme bulunmaktadır. Bu kümelerden arka plan olarak seçilen cilt kısmında ve ön plan olarak seçilen melanomlu alanlarda renk ağırlıkları birbirine yakın değerler vermektedir. Bu nedenle yapılan bu çalışma kapsamında, kullanılan Kortalama kümeleme algoritmasında k merkez değerlerinin; alınan makroskopik görüntülerde sonuçları etkileyecek ve gürültü oluşturabilecek arka plan değerleri çok fazla olmadığı için, 2 ve 4 olarak seçilmesi uygun görülmüştür.

K merkez değerleri sırasıyla 2 ve 4 seçilerek, tüm görüntüler ayrı ayrı kullanılarak sistem test edilmiştir. Sistemin etkinliğini ölçmek için, elde edilen değerler PSNR ve CC metrikleri kullanılarak analiz edilmiştir. CC yöntemi, değişkenler arasındaki ilişkiyi temsil etmek için kullanılmaktadır. Sonuçlar -1 ile +1 arasındadır. Negatif değerler negatif ilişki, pozitif değerler pozitif bir ilişki, değerler 1 veya -1 olduğunda ise mükemmel bir ilişki olduğunu göstermektedir. CC, Denklem 2 kullanılarak hesaplanmaktadır.

$$
C=\frac{\operatorname{cov}(X, Y)}{\sigma_{x} \sigma_{y}}
$$

Denklem 2'de $\operatorname{cov}(X, Y)$ işleme sokulan her iki görüntünün kovaryans değerini, $\sigma_{x}$ ve $\sigma_{y}$ sırasıyla $\mathrm{X}$ ve $\mathrm{Y}$ görüntülerinin standart sapmasını ifade etmektedir [20]. PSNR metodu, bir sinyalin maksimum gücü ile karelerinin ortalamasının beklenen değeri arasındaki oranı vermektedir. PSNR oranının yüksek çıkması görüntünün bozulma gürültüsüne oranla daha güçlü olduğunu göstermektedir [21]. PSNR değeri Denklem 3 kullanılarak elde edilmektedir [3].

$$
P S N R=-10 \log _{10} \frac{M S E}{S^{2}}
$$


Denklem 3'de gösterilen $S^{2}$, görüntüde yer alan en büyük pikseli ifade etmektedir. Tablo 1'de K merkezi 2 kullanılarak elde edilen sonuçlardan en yüksek ve en düşük PSNR değerini veren görüntüler ve PSNR değerleri verilmektedir.

Tablo 1. $K=2$ için En Düşük ve En Yüksek PSNR Değerlerini Veren Sonuçlar

\begin{tabular}{ccccc}
\hline ID & Çözzünürlük & $\begin{array}{c}\text { PSNR } \\
(d B)\end{array}$ & Orijinal & Sistem Çıktısı \\
\hline 65 & $1153 \times 1509$ & 7,7185 & & \\
& & & \\
25 & $641 \times 337$ & 16,5451 & & \\
\hline
\end{tabular}

Tablo 2. $K=4$ için En Düşük ve En Yüksek PSNR Değerlerini Veren Sonuçlar

\begin{tabular}{|c|c|c|c|c|}
\hline$I D$ & Çözünnürlük & $\begin{array}{c}\text { PSNR } \\
(d B)\end{array}$ & Orijinal & Sistem Çıktıs \\
\hline 65 & $1153 \times 1509$ & 7,7291 & & \\
\hline 25 & $641 \times 337$ & 17,1591 & & \\
\hline
\end{tabular}

Tablo 3. $K=2$ ve $K=4$ Merkezlerinin CC, PSNR Metrik Sonuçları ve Algoritma Çalışma Süreleri

\begin{tabular}{cccc}
\hline Merkez Saytsi & CC & $\begin{array}{c}\text { PSNR } \\
(d B)\end{array}$ & $\begin{array}{c}\text { Süre } \\
(\text { Sn. })\end{array}$ \\
\hline \multirow{2}{*}{2} & 0,7503 & 16,5451 & 0,1543 \\
& 0,7568 & 16,4836 & 0,4209 \\
& 0,8526 & 15,9543 & 0,8066 \\
& 0,8412 & 15,8470 & 1,8881 \\
\hline \multirow{4}{*}{4} & 0,8948 & $\mathbf{1 7 , 1 5 9 1}$ & 1,0609 \\
& 0,8995 & 17,0413 & 1,0016 \\
& 0,9573 & 17,0173 & 0,8475 \\
& 0,8991 & 16,6146 & 0,9403 \\
\hline
\end{tabular}

Tablo 2'de K merkezi 4 kullanılarak elde edilen sonuçlardan en yüksek ve en düşük PSNR değerini veren görüntüler ve PSNR değerleri verilmektedir. Tablo 1 ve 2 incelendiğinde, $K$ merkez değeri ikiden dörde çıkarıldığında yüksek çözünürlüklü görüntülerde PSNR değerinin yavaş arttığı, düşük çözünürlüklü görüntülerde ise $0,61 \mathrm{~dB}$ gibi yüksek bir artış yaşadığı gözlemlenmektedir.

Tablo 3'te ise K merkezi 2 ve 4 ile elde edilen sonuçlardan en yüksek PSNR değerine sahip 4 görüntünün PSNR, CC ve süre değerleri gösterilmektedir. Tablo 3 incelendiğinde yüksek PSNR değerini veren sonuçlar $\mathrm{K}$ merkez sayısı 4 seçildiğinde elde edilmektedir. Ayrıca CC değerlerinin de K merkez değeri arttırıldığında 1'e yaklaştığı tespit edilmektedir. Görüntünün çözünürlüğüne ve seçilen K merkez sayısına bağlı olarak 
algoritma çalışma sürelerinin değiştiği gözlemlenmektedir. Fakat yüksek PSNR değerinin sistem başarımına olan katkısı düşünüldügünde sistemin makroskopik cilt görüntüleri üzerinde lezyon bölütleme işlemlerinde $\mathrm{K}$ merkez değeri 4 seçilerek kullanılması gerektiği tespit edilmektedir.

Yapılan bu çalışmanın verimliliği, daha önce tarafımızca yapılan iyileştirilmiş Canny kenar belirleme algoritması [22] ve ortalama kayma algoritması [23] ile karşılaştırılarak elde edilmiştir. Karşılaştırma yapılan bu üç algoritmada da aynı veri kümesi ve aynı metrikler kullanılmıştır. Tablo 3' de gözlemlendiği gibi, $\mathrm{K}=4$ değeri 2'den daha başarılı sonuçlar vermektedir. Dolayısıyla önceki çalışmalarla yapılan karşılaştırmalar K merkez değeri 4 seçilerek yapılmıştır. Tablo 4'te, test aşamasında kullanılan bazı görüntülere ait işlem süresi, PSNR ve CC metrik değerleri gösterilmektedir.

Tablo 4. Görüntülerin Isşlem Süresi, PSNR ve CC Metrik Sonuçları

\begin{tabular}{|c|c|c|c|c|c|c|c|c|c|}
\hline \multicolumn{4}{|c|}{ Ortalama Kayma Alg. } & \multicolumn{3}{|c|}{$\begin{array}{l}\text { Iyileştirilmis Canny } \\
\text { Kenar Belirleme Alg. }\end{array}$} & \multicolumn{3}{|c|}{$\begin{array}{c}\text { Önerilen } \\
(K=4)\end{array}$} \\
\hline$I D$ & $\begin{array}{l}\text { Süre } \\
\text { (Sn.) }\end{array}$ & $\begin{array}{c}P S N R \\
(d B)\end{array}$ & $C C$ & $\begin{array}{l}\text { Süre } \\
(S n .)\end{array}$ & $\begin{array}{c}P S N R \\
(d B)\end{array}$ & $C C$ & $\begin{array}{l}\text { Süre } \\
(S n .)\end{array}$ & $\begin{array}{c}P S N R \\
(d B)\end{array}$ & $C C$ \\
\hline 1 & 39.2 & 7.7 & 0.70 & 26.8 & 3.9 & 0.008 & 0.33 & 10.9 & 0.91 \\
\hline 8 & 44.0 & 7.8 & 0.63 & 28.0 & 3.7 & -0.023 & 0.43 & 12.88 & 0.95 \\
\hline 57 & 15.4 & 7.4 & 0.14 & 17.1 & 3.5 & 0.018 & 0.26 & 8.99 & 0.89 \\
\hline
\end{tabular}

Tablo 4 incelendiğinde, en başarılı sonuçların $\mathrm{K}$ merkez değeri 4 seçildiğinde elde edildiği ve aynı zamanda önerilen sistemin en yüksek PSNR değerine, sistem çalışma süresi ve korelasyon katsayısı bakımından da en efektif değerlere sahip olduğu görülmektedir. Tablo 5'te iyileștirilmiş Canny kenar belirleme, ortalama kayma algoritmaları ve önerilen sistemde en yüksek PSNR değerini, Tablo 6'da en düşük PSNR değerini veren görüntüler gösterilmektedir. Tablo 5 ve Tablo 6 birlikte incelendiğinde en başarılı sonucun önerilen sistemle alındığ gözlemlenmektedir.

Tablo 5. Test Aşamasında Kullanılan Algoritmaların En Yüksek PSNR Değerini Veren Görüntü Sonuçları

\begin{tabular}{lcc}
\hline \multicolumn{1}{c}{ Metot } & $\begin{array}{c}\text { PSNR } \\
(d B)\end{array}$ & Orijinal Görüntï Sistem Çıtıs \\
Ortalama Kayma Alg. & 11,78 \\
& \\
Canny Kenar Blr. Alg. & 7,60 \\
$\begin{array}{l}\text { Onerilen } \\
\text { (K=4) }\end{array}$ & $\mathbf{1 7 , 1 5}$ \\
&
\end{tabular}


Tablo 6. Test Aşamasında Kullanılan Algoritmaların En Düşük PSNR Değerini Veren Görüntü Sonuçları

\begin{tabular}{|c|c|c|c|}
\hline Metot & $\begin{array}{c}\text { PSNR } \\
(d B)\end{array}$ & Orijinal Görüntü & Sistem Çıktısı \\
\hline Ortalama Kayma Alg. & 4,97 & & \\
\hline Canny Kenar Blr. Alg. & 2,59 & & \\
\hline $\begin{array}{l}\text { Önerilen } \\
(K=4)\end{array}$ & 7,72 & & \\
\hline
\end{tabular}

\section{SONUÇ (CONCLUSION)}

Melanom cilt kanseri, erken teşhislerde oldukça yüksek tedavi şansının olduğu cilt kanseri türleri arasında bulunmaktadır. Agresif bir şekilde ilerleyen melanomun teşhisi çoğunlukla cilt üzerinde yapılan görsel incelemelerle yapılmaktadır. Dolayısıyla yapılan değerlendirmeler sübjektif olmaktadır. Bu çalışmanın amacı doğru teşhis oranlarını artırmak için, lezyon alanlarının sayısal olarak elde edilmesi işlemidir. Bu işlemi gerçekleştirmek için irdelenen problem, kümeleme algoritması kullanılarak ele alınmaktadır. Çalışma kapsamında elde edilen lezyon bölgeleri ve lezyon olmayan bölgeler renk değerlerine göre kümelenmektedir. Renk değerlerine göre elde edilen kümeler, bizlere ileriki çalışmalarda kullanılmak üzere gerekli lezyon bölge sınırlarını ve lezyonların renk bilgilerini vermektedir.

Yapılan bu çalışmada dermoskopik görüntülerde lezyon bölütleme işlemlerinde temel bölütleme algoritması olarak K-ortalama kümeleme algoritması kullanılmış ve K merkezi sayısı (küme sayısı) 2 ve 4 değerleri seçilerek sistem test edilmiştir. Kümeleme algoritması olarak, literatürde yapılan çalışmalarda çok sık kullanılması ve başarılı sonuçlar vermesinden dolayı K-ortalama kümeleme yöntemi seçilmiştir. Elde edilen değerlerin analiz işlemleri, her bir merkez için ayrı ayrı PSNR ve CC metrikleri kullanılarak gerçekleştirilmiştir. Aynı zamanda sistemin çalışma süreleri de hesaplanmıştır. Çalışmanın başarımını ölçmek için sistem iyileştirilmiş Canny kenar belirleme algoritması ve ortalama kayma algoritması kullanılarak elde edilen metrik sonuçlarıyla karşılaştırılmış olup yüksek PSNR değerlerinin k merkez sayısı 4 seçildiğinde elde edildiği tespit edilmiştir. Yüksek PSNR değerinin sistem başarımını arttırdığı ve aynı zamanda seçilen merkez sayısı ile doğru orantılı olarak algoritma çalışma sürelerinin de arttı̆̆ gözlemlenmiştir.

Metrik sonuçlar incelendiğinde, yapılan bu çalışmada dermoskopik görüntülerde lezyon bölütleme işlemlerinde temel bölütleme algoritması olarak K-ortalama kümeleme algoritması kullanıldığında ve merkez sayısı 4 seçildiğinde makroskopik melanomlu cilt görüntüleri üzerindeki lezyon bölütleme işleminin daha başarılı sonuçlar verdiği tespit edilmiştir.

Gelecekteki çalışmada, bu çalışmadan elde edilen kümelerin bir sınıflama algoritmasında kullanılarak sistemin lezyon bölütleme işlemini akıllı bir şekilde gerçekleştirmesi beklenmektedir. 


\section{KAYNAKLAR (REFERENCES)}

[1] Çoban, L. Cilt (Deri) Kanseri Belirtileri, Tedavisi ve Korunma Yöntemleri. https://www.memorial.com.tr/saglik-rehberleri/cilt-deri-kanseri-belirtileri-tedavisi-ve-korunmayontemleri/. (Ziyaret Tarihi: 15.09.2019).

[2] Ganster, H., Pinz, P., Rohrer, R., Wildling, E., Binder, M., \& Kittler, H. (2011). Automated Melanoma Recognition. IEEE Transactions on Medical Imaging, 20(3), 233-239.

[3] Altuncu, M.A., Gülağız, F.K., Hangisi, F.S., \& Şahin, S. (2017). Performance Analysis of Image Restoration Techniques for Dermoscopy Images. International Journal of Applied Information Systems, 11(8), 15-19.

[4] Alsmadi, M. K. (2018). A hybrid Fuzzy C-Means and Neutrosophic for jaw lesions segmentation. Ain Shams Engineering Journal, 9(4), 697-706.

[5] Maglogiannis I., Pavlopoulos S., \& Koutsouris D. (2005). An integrated computer supported acquisition, handling, and characterization system for pigmented skin lesions in dermatological images. IEEE Transactions on Information Technology in Biomedicine, 9(1), 86-98.

[6] Pires I.M., \& Garcia N.M. (2015). Wound Area Assessment using Mobile Application, In Biodevices, Lisbon, Portugal, 271-282.

[7] Abbas A.A., Guo X., Tan W.H., \& Jalab H.A. (2014). Combined spline and B-spline for an improved automatic skin lesion segmentation in dermoscopic images using optimal color channel. Journal of medical systems, 38(8), 80 .

[8] Celebi M.E., Kingravi H.A., Iyatomi H., Aslandogan A.Y., Stoecker W.V., Moss R.H., Malters J.M., Grichnik J.M., Marghoob A.A., Rabinovitz H.S., \& Menzies S.W. (2008). Border detection in dermoscopy images using statistical region merging. Skin Research and Technology, 14(3), 347-353.

[9] Wantanajittikul, K., Auephanwiriyakul, S., Theera-Umpon, N., \& Koanantakool, T. (2012). Automatic segmentation and degree identification in burn color images, The 4th 2011 Biomedical Engineering International Conference, 169-173.

[10] Haider A., Alhashim M., Tavakolian K., \& Fazel-Rezai R. (2016). Computer-assisted image processing technique for tracking wound progress. In Electro Information Technology (EIT), 2016 IEEE International Conference, Grand Forks, ND, USA, 0750-0754.

[11] MacQueen, J. B. (1967). Some Methods for classification and Analysis of Multivariate Observations. Proceedings of 5-th Berkeley Symposium on Mathematical Statistics and Probability, 1, 281-297.

[12] Sarıman, G. (2011). Veri madenciliğinde kümeleme teknikleri üzerine bir çalışma: k-means ve kmedoids kümeleme algoritmalarının karşılaştırılması. Süleyman Demirel Üniversitesi Fen Bilimleri Enstitüsü Dergisi, 15(3).

[13] Cebecı, Z., Yıldız, F., \& Kayaalp, G. T. (2015). K-ortalamalar kümelemesinde optimum K değeri seçilmesi. 2. Ulusal Yönetim Bilişim Sistemleri Kongresi, 8-10.

[14] Işık, M., \& Çamurcu, A.Y. (2007). K-means, k-medoids ve bulanık c-means algoritmalarının uygulamalı olarak performanslarının tespiti. İstanbul Ticaret Üniversitesi Fen Bilimleri Dergisi, 6(11), $31-45$.

[15] Pang-Ning Tan, P. N., Steinbach, M., \& Kumar, V. (2006). Introduction to Data Mining, Addison Wesley Publishers, Boston. 
[16] Giotis, I., Molders, N., Land, S., Biehl, M., Jonkman, M.F., \& Petkov, N. (2015). MED-NODE: A computer-assisted melanoma diagnosis system using non-dermoscopic images. Expert Systems with Applications, 42, 6578-6585.

[17] Pham, D. T., Dimov, S. S., \& Nguyen, C. D. (2005). Selection of K in K-means clustering. Proceedings of the Institution of Mechanical Engineers, Part C: Journal of Mechanical Engineering Science, 219(1), 103-119.

[18] Dinçer, E., \& N. Duru. (2006). Grrtlak Kanseri Ameliyat Verilerinin K-means Yöntemiyle Analizi. Türkiye Bilişim Vakfı Bilgisayar Bilimleri ve Mühendisliği Dergisi, 2(1).

[19] Cebeci, Z., Yıldız, F., \& Kayaalp, G.T. (2015). K-Ortalamalar Kümelemesinde Optimum K Değeri Seçilmesi. 2. Ulusal Yönetim Bilişim Sistemleri Kongresi Bildiriler Kitabı, 231-242.

[20] Lee, R. J, \& Nicewander, W. A. (1988). Thirteen ways to look at the correlation coefficient. The American Statistician, 42(1), 59-66.

[21] Avcı, D. (2015). İdrar imgelerinden hücrelerin tanınması ve sayımı için steganografik yöntemler tabanlı güvenli bir karar destek sistemi, Doktora Tezi, Fırat Üniversitesi Fen Bilimleri Enstitüsü, Elazı̆g.

[22] İlkin, S., Gülağız, F.K., Hangişi F.S., \& Şahin, S. (2018). Computer Aided Wound Area Detection System for Dermatological Images. Cham: Springer: Trends and Advances in Information Systems and Technologies. WorldCIST'18 2018. Advances in Intelligent Systems and Computing, 746, 820830 .

[23] İlkin, S., Tayfur, T., \& Şahin, S. (2018). Ortalama Kayma Algoritması Kullanılarak Dermatolojik Görüntüler Üzerindeki Melanomlu Alanların Tespiti. IMASCON Uluslararası Marmara Fen ve Sosyal Bilimler Kongresi 2018, 780-787. 